\title{
Can We Have a "Do-over"? Disrupting a Half-century Old Approach to Child Abuse and Neglect
}

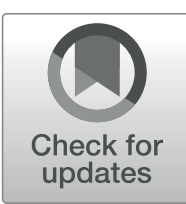

\author{
Richard D. Krugman ${ }^{1,2} \cdot$ Lori E. Poland ${ }^{2}$
}

Published online: 23 March 2020

(C) The Author(s) 2020

Working in an academic hospital unit then known as the National Center for the Prevention and Treatment of Child Abuse and Neglect (now The Kempe Center at the University of Colorado Anschutz Medical Campus), C. Henry Kempe and his colleagues published several books and papers providing practical guidance for health professionals and educators concerned about child maltreatment. These publications focused on recognition of children who had experienced abuse and neglect, treatment of such children and their families with social and mental health services, and prediction and prevention of child abuse and neglect in the perinatal period (e.g., Gray et al. 1979; Kempe and Helfer 1980). The multidisciplinary approaches described in these publications were based on efforts originating with the identification of the battered child syndrome in the 1960s (Kempe et al. 1962) and developed and tested in the 1970s after the state-by-state adoption of child abuse reporting laws and corollary establishment of public-sector child protection systems (see generally Krugman and Korbin 2013).

\section{Child Protection in the Contexts of Child Welfare and Pediatric Health Care}

In Colorado in the mid-twentieth century, Child Protective Services (CPS; the specialty child welfare agency charged with protection of children from maltreatment) and juvenile courts were generally perceived to be helpful to families and to have the resources to provide services to families who needed them (primarily families where there was physical abuse, intimate partner violence, and neglect). With the surge in public awareness of child sexual abuse during the late 1970s and the 1980s, CPS lost its

Richard D. Krugman

RichardKrugman@EndCAN.org

1 University of Colorado School of Medicine, Aurora, USA

2 The National Foundation to End Child Abuse and Neglect, PO Box 102428, Denver, CO 80250, USA 
capacity to be as effective as its advocates and leaders had hoped. As reports of suspected abuse of all kinds increased at an explosive rate, CPS's legally mandated focus on receipt and investigation of a vastly increasing number of reports ("What happened?") tragically diminished its capacity to provide services in response ("What can we do to help?"); see U.S. Advisory Board on Child Abuse and Neglect (1993). During the 1980s alone, reports of suspected cases of abuse and neglect approximately tripled. As the U.S. Advisory Board (1993) summarized, the number of reports escalated "from an estimate of a few hundred cases in the early 1960s to reports of 60,000 cases in 1974 (when the Child Abuse Prevention and Treatment Act was enacted), 1.1 million cases in 1980, 2.4 million cases in 1989, and nearly three million cases in 1992" (U.S. Advisory Board 1993, p. 8, footnote omitted).

The tragic consequences of this scale of engagement were magnified by related political and social effects of the system's seemingly single-minded forensic focus. The investigatory process and the criminal consequences of suspected cases of child sexual abuse contributed to a significant backlash toward CPS (Hechler 1988). At the same time, news reports documented that $30-50 \%$ of the children who died of abuse had an open case with CPS.

These developments led to the legislative formation of the U.S. Advisory Board on Child Abuse and Neglect. In the early 1990s, the U.S. Advisory Board issued several reports to advise Congress, the Administration, the child protection field, and the general public about how to address the problem of child maltreatment. The U.S. Advisory Board's approach was ambitious and stepwise: (a) proclaiming a national emergency in the child protection system, (b) calling for a federal focus on strengthening comprehensive community responses to child maltreatment, (c) framing this effort in relation to international norms for protection of children's rights, (d) articulating a new national child-centered, neighborhood-based strategy for child protection, and (e) applying this strategy specifically to the tragic problem of fatalities resulting from child maltreatment. Unfortunately, however, the U.S. Advisory Board's expansive but specific recommendations were, for the most part, ignored. (For more details on the history of the U.S. Advisory Board, possible reasons for its limited effect on policy, and a cautiously optimistic view of its generational influence on understanding of child maltreatment, see Metrikin-Gold (2015). A similar analysis was undertaken by Melton (2002) in the first decade after the U.S. Advisory Board's (1993) proposal for a new national child protection policy.)

In contrast, over the past half-century, the outlook for children with serious pediatric illness has dramatically improved. The mortality for children with cancer, cystic fibrosis, prematurity, infectious meningitis, type I diabetes, congenital heart disease, HIV, and many other conditions is significantly better than it was 40 years ago. During those years, not-for-profit private foundations formed to collect donations from individuals and corporations to support research, training, and clinical programs focusing on specific diseases (e.g., leukemia, juvenile diabetes, cystic fibrosis) or, more broadly, diseases of nearly every organ of the body (e.g., heart, lung, kidney, liver). These nonprofits have worked alongside other entities, such as the National Health Council and Research!America, to lobby the U.S. Congress for billions of dollars in appropriations to the National Institutes of Health (NIH) for basic and clinical research. The result has been dramatic reduction in the morbidity and mortality of pediatric disease. 
A glaring exception to this positive story has been the striking paucity of funding for research and training in the prevention and treatment of child abuse and neglect. Five children a day have died because of abuse or neglect for most of the last 50 years while progress has been made elsewhere. It is now clear that the downstream effects of child abuse and neglect are associated with a host of health and mental disorders (e.g., Felitti et al. 1998). Nevertheless, the health side of the Department of Health and Human Services has historically viewed abuse and neglect as a social problem best handled by the Office on Child Abuse and Neglect, which is buried in the Children's Bureau on the human services side of the agency. Furthermore, there appear to be dozens of NIH grant programs and nonprofit foundations raising funds for suicide prevention, eating disorders, alcohol and substance abuse, depression, cancer, heart disease, and other illnesses. Missing from the list of grants is the study of abuse and neglect - one of the etiologies of the disorders that are currently foci of funding.

\section{The National Foundation to End Child Abuse and Neglect}

\section{Background}

One of The National Foundation to End Child Abuse and Neglect (EndCAN's) founders (Krugman) was introduced to a career in the field of child protection more than 50 years ago. As a third-year medical student, he heard Kempe lecture on battered child syndrome. Two years later, as a pediatrics intern at the University of Colorado School of Medicine, he saw his first case - a 5-month-old infant who had been beaten to death by his mother. Kempe, the attending physician, asked Krugman to present the case at a morbidity and mortality conference happening the next week. In reviewing case records, it became clear that any one of 27 health and child welfare professionals who interacted with the mother and her baby over a 7-month period could have prevented the death of the baby. However, none did - a story of egregiously compounded negligence that left an indelible impression on Krugman and that shaped his thinking about the field that has long drawn his attention as an administrator, advocate, clinician, editor, educator, and researcher.

During Krugman's residency (1968-1971), he cared for hundreds of children with serious health problems [e.g., prematurity (less than 34 weeks gestation), cystic fibrosis, acute lymphocytic leukemia, congenital heart defects, and bacterial meningitis]. In the 1960 s and early 1970 s, most of the children with serious conditions whom he treated died or experienced terrible negative effects on their development. Over his decades as a pediatrician, Krugman has seen many advancements that have resulted in improved outcomes for children with conditions that had life-threatening consequences when he was early in his career. The same cannot be said for child abuse and neglect.

The other founder of EndCAN (Poland) is a mental health therapist who also serves as executive director of EndCAN. The nature and goals of her work and the passion that motivates it are informed by her experience as a child abuse survivor, who was a victim of kidnapping, sexual abuse, and attempted murder in 1983 (Jones and Krugman 1986). 
Much of Poland's work focuses on the messaging and conversation around child abuse and neglect. She believes that shame has a significant role in the prevalence of abuse and neglect; it is the reason why millions of survivors, thrivers, and transcenders do not speak about their own abuse. Instead, they keep their experience "buttoned up" and carry on with life. Poland further believes that victims can have a significant impact on the field by (a) improving understanding of how some individuals "make it out" while others continue to struggle, (b) uniting their voices to stand up against abuse, and (c) showing that the majority of people who were once abused do not grow up to be abusers themselves.

The co-founders kept in touch over the years. In 2015, when Krugman's term as dean of the medical school ended, he and Poland decided to work together to start EndCAN, with the mission of ending child abuse and neglect in their lifetime. There were several reasons behind the decision to start a foundation. Of course, the need to increase support for research and prevention was paramount. In that context, a particular determinant was the increasing recognition that abuse and neglect are not only social and legal problems but that they are also properly framed as physical, mental, and public health issues.

In building EndCAN, organizational models have included dozens of existing successful foundations, such as the March of Dimes, the American Heart Association, and the Juvenile Diabetes Foundation. These organizations have supported research, training, treatment, prevention, and advocacy for decades. A recent example is the $600 \%$ increase of funding over the last 6 years (to $\$ 98$ million) by the Global Down Syndrome Foundation. The co-founders and supporters of EndCAN believe that such philanthropic efforts have contributed significantly to reduction of the morbidity and mortality of the diseases that the relevant foundations address.

During the planning stage, visits were made with several foundations to ask whether they saw the need for a foundation focused on child abuse and neglect. Most individuals expressed surprise that there was not already such a foundation. When they learned there was not, the typical response was, "There should be."

EndCAN was incorporated in December 2017, and it received notice of its taxexempt status in April 2018. There were two public launches for EndCAN, one in June 2018 at the Colorado State Capitol and the other in September 2018 at the National Press Club in Washington, DC. In September 2018, EndCAN received a "\$500,000 grant from the Robert Wood Johnson Foundation for general operating support.

\section{The Approach: Public Awareness}

The first task for the foundation was to develop and implement a public awareness program aimed at changing the public perception of child abuse and neglect from primarily a social and legal problem to one that is also a physical, mental, and public health problem. We believe that the 40-year responsibility of child welfare, law enforcement, and the courts for receiving and investigating reports of child maltreatment has led to a public perception that abuse and neglect are social and legal issues. 
There has never been such an effort for research on child abuse and neglect. Creating a community of survivors who speak openly and without shame about their survival and ability to thrive in their lives will give hope and connection to others. The shame and stigma associated with being a victim, a perpetrator, and even a bystander of abuse must be overcome (Krugman 2019). To implement such a campaign will require \$3-\$4 million annually. We hope to work with other national child- and family-focused programs (e.g., Zero to Three, Prevent Child Abuse America, Casey Family Programs) to seek corporate support for such an effort.

One of the challenges for EndCAN is to identify and reach the appropriate advocacy group. When a child is diagnosed with diabetes or an adult is diagnosed with Parkinson's disease, for example, the family is immediately connected with the local or national organization that supports people with that disease. It was clear from the outset that families with CPS involvement were not a likely advocacy group. What was clear, however, was that there are millions of adult survivors of all forms of child abuse and neglect - many, if not most, of whom have never been involved with CPS - who could be that advocacy group.

We face several challenges in reaching these individuals:

1. Because of shame and stigma, adult survivors rarely talk about their experience.

2. Gaze aversion is practiced by the public and professionals who do not want to talk about abuse and neglect.

3. Effective strategies for reaching adult survivors of child maltreatment are not obvious.

To address these challenges, we worked in our first year with two organizations (Ogilvy in New York City and Fortnight Collective in Boulder, CO) to create social media campaigns. Two of these campaigns ("Louder than Silence" and "We Are All Survivors") can be found on the EndCAN website (https://www.endcan.org).

\section{The Approach: Grants and Contracts Awarded}

Our first contract was with Research!America. To measure the impact of the public awareness campaign, we commissioned a baseline national survey to gauge public thought about child abuse and neglect. About two-fifths (42\%) of individuals surveyed viewed child abuse and neglect as a serious public health problem (Research!America 2018). In that regard, child maltreatment ranked below drug abuse (67\%), cancer (55\%), and obesity (46\%) but above heart disease (39\%) and Alzheimer's (34\%). We intend to repeat this survey in the coming years in order to monitor the impact of our national public information campaigns.

A decade ago, the American Board of Pediatrics created the subspecialty of child abuse pediatrics (CAP). In its first year as part of an effort to enhance human resources in the field, EndCAN solicited application and funded three first-year fellows at the University of Pennsylvania, University of Toronto, and Baylor University. The grant program awarded a total of $\$ 50,000$ annually to the three fellowship programs.

There are 21 CAP fellowship programs in the USA. Unlike the fellowship programs for oncology, cardiology, neonatology, and a myriad of other specialties, however, there is no NIH funding for research and training. As a result, the CAP 
fellows get relatively little training in research. Most of their work-like the workload of the field - has migrated toward clinical forensic work within the civil and criminal justice systems. Our belief is that an academic subspecialty needs an external funding source for its growth and development. Accordingly, in the past year, EndCAN has partnered with the Helfer Society to solicit funding and to continue to expand this grant program.

\section{The Approach: Disruption Papers}

Another first-year funding initiative for EndCAN was to invite disruption papers. The state of the research, training, clinical, and prevention sectors of the field of child abuse and neglect have been such that it seemed unwise to raise money to fund "more of the same." Rather than assuming the best course to follow, EndCAN invited colleagues around the country to propose solutions. The question posed was: If we were starting over (knowing everything we know from 50 years of doing this work), how should we construct the ideal research, training, clinical, and prevention programs to assure that all abused and neglected children and their families would get the treatment, care, and support that they needed throughout the lifespan (whether the abuse was intrafamilial or extrafamilial)? Furthermore, what would we need to do to assure that all 3-4 million children born in the USA each year grow up in an abuse- and neglect-free environment?

The initial stage was to request letters of intent from those interested in participating. Fifty-six teams or individuals responded. After a panel review, 22 finalists were invited to submit papers. The papers were blinded and then underwent peer review by a panel of 16 clinical and research professionals. The winning papers for three of the four categories (prevention, research, and clinical) were awarded $\$ 10,000$ prizes and are published in this issue of the International Journal on Child Maltreatment. Also published in this issue are three papers that received honorable mention awards in the same categories. There were no winning papers in the training category. (At the time this editorial was submitted, five finalists were working on papers on the topic of training.) This issue also includes papers written by Nigel Parton and by Todd Herrenkohl and his colleagues. Their papers were included because of their fit with the theme of exploring new approaches to child protection. Parton and the Herrenkohl team also bring an international flavor to the question of reform, especially as applied in wealthy English-speaking countries.

Our hope is that this compilation of work will stimulate innovation and discussion for the field. It is abundantly clear that the status quo is inadequate. The current system of child protection fails to demonstrate effectiveness in identifying abuse and neglect and in ameliorating and intervening in a way that assures healthy children and families. Furthermore, the current system (like the society at large) does nothing for the hundreds of thousands of children who are abused outside the family. We need to do better.

Some individuals will view these papers as being "too disruptive," while others may not find them disruptive enough. The conversation, however, is a start. The goal is for readers of this journal to appreciate them for what they are and to begin to think "outside the box" in their own community or legal jurisdiction to see whether we can begin to climb out of what feels to some who have been doing this for a long time, a 40-year rut. 
Acknowledgment Acknowledgment is given to Jill McLeigh and Gary Melton for their editorial assistance in the completion of this article for publication.

\section{Compliance with Ethical Standards}

Conflict of Interest The authors have no financial conflicts of interest. They are co-founders of The National Foundation to End Child Abuse and Neglect. Krugman is chair, and Poland is executive director.

Open Access This article is licensed under a Creative Commons Attribution 4.0 International License, which permits use, sharing, adaptation, distribution and reproduction in any medium or format, as long as you give appropriate credit to the original author(s) and the source, provide a link to the Creative Commons licence, and indicate if changes were made. The images or other third party material in this article are included in the article's Creative Commons licence, unless indicated otherwise in a credit line to the material. If material is not included in the article's Creative Commons licence and your intended use is not permitted by statutory regulation or exceeds the permitted use, you will need to obtain permission directly from the copyright holder. To view a copy of this licence, visit http://creativecommons.org/licenses/by/4.0/.

\section{References}

Felitti, V. J., Anda, R. F., Nordenberg, D., Williamson, D. F., Spitz, A. M., Edwards, V., Koss, M. P., \& Marks, J. S. (1998). Relationship of childhood abuse and household dysfunction to many of the leading causes of death in adults: the Adverse Childhood Experiences (ACE) Study. American Journal of Preventive Medicine, 14, 245-258.

Gray, J., Cutler, C., Dean, J., \& Kempe, C. H. (1979). Prediction and prevention of child abuse and neglect. Journal of Social Issues, 35, 127-139.

Hechler, D. (1988). The battle and the backlash: the child sexual abuse wars. New York, NY: Macmillan.

Jones, D. P., \& Krugman, R. D. (1986). Can a 3-year-old child bear witness to her sexual assault and attempted murder? Child Abuse \& Neglect, 10, 253-258.

Kempe, C. H., \& Helfer, R. E. (1980). The battered child (3rd ed.). Chicago, IL: University of Chicago Press.

Kempe, C. H., Silverman, F. N., Steele, B. F., Droegemueller, W., \& Silver, H. K. (1962). The battered-child syndrome. Journal of the American Medical Association, 181(1), 17-24.

Krugman, R. D. (2019). Ending gaze aversion to child abuse and neglect. Health Affairs, 38, 1762-1765.

Krugman, R. D., \& Korbin, J. E. (Eds.). (2013). C. Henry Kempe: a 50 year legacy to the field of child abuse and neglect. Dordrecht, The Netherlands: Springer.

Melton, G. B. (2002). Chronic neglect of family violence: more than a decade of reports to guide U.S. policy. Child Abuse \& Neglect, 26, 569-586.

Metrikin-Gold, B. D. (2015). Personal reflections about the work of the U.S. advisory board on child abuse and neglect. Child Abuse \& Neglect, 41, 3-18.

Research!America. (2018). America's views on child abuse and neglect. Retrieved from https://www. researchamerica.org. Accessed May 2018

U. S. Advisory Board on Child Abuse and Neglect. (1993). Neighbors helping neighbors: a new national strategy for the protection of children. Washington, DC: U.S. Government Printing Office.

Publisher's Note Springer Nature remains neutral with regard to jurisdictional claims in published maps and institutional affiliations. 